\title{
Response of Red Cabbage (Brassica oleracea L. var. capitata f. rubra) to Different Levels of Plant and Row Spacing
}

\author{
S. Manasa , L. Mukunda Lakshmi, Syed Sadarunnisa and T. Rajasekharam \\ College of Horticulture, Anantharajupeta, Dr. Y.S.R. Horticultural University, \\ Andhra Pradesh, India \\ *Corresponding author
}

\section{A B S T R A C T}

\begin{tabular}{|l|}
\hline Ke y w or d s \\
Red cabbage, Spacing, \\
Yield components, \\
Yield.
\end{tabular}

\section{Keywords}

Red cabbage, Spacing,

Yield components,

Article Info

Accepted:

15 September 2017

10 November 2017
The experiment was undertaken to determine the effect of different plant and row spacing on yield attributes and yield of red cabbage. Three different spacings were taken viz., 45x45 cm, 60x45 cm and 60x60 cm. Variety Red Jewel was used for the study. The results demonstrated that plant spacing had significant effects on yield components and yield of red cabbage. Significantly wider spacing produced higher size of head circumference, volume and compactness. Fresh weight and dry matter production also have the same trend in wider spacing. The weight of individual red cabbage head $(1.15 \mathrm{~kg})$ was increased with the widest spacing of $60 \times 60 \mathrm{~cm}$. On the contrary, the yield per plot and marketable yield were the highest $(23.80 \mathrm{~kg} /$ plot and $183.69 \mathrm{q} / \mathrm{ha}$, respectively) at the closest spacing (45 $\mathrm{x} 45 \mathrm{~cm})$ and the lowest $(16.23 \mathrm{~kg} / \mathrm{plot}$ and $125.21 \mathrm{q} / \mathrm{ha})$ was at widest spacing $(60 \times 60 \mathrm{~cm})$.

\section{Introduction}

Red cabbage (Brassica oleracea L. var. capitata f. rubra) is one of the most important cool season vegetables belongs to the family Cruciferae. It is an herbaceous plant distinguished by a short stem upon which is crown with a mass of red colored leaves (head). It is used as salad, boiled vegetable, cooked in curries, used in pickling as well as dehydrated vegetable. Red cabbage is known to possess medicinal properties. It has an anticancer property due to the presence of indole-3-carbinol. Red cabbage is an excellent source of vitamin $\mathrm{C}$, in addition to containing vitamin B complex, red cabbage supplies some potassium and calcium to the diet.
Red cabbage distinguished by exceptional health-enhancing properties and many beneficial sensory traits, has become more and more important in recent years (Wojciechowska et al., 2007). In India, cabbage including red cabbage is cultivated in an area of 388 thousand ha producing 8755 thousand MT (Anonymous, 2015-16). In Andhra Pradesh, the crops are cultivated in 5.43 thousand ha with a production of 81.45 thousand tonnes.

Apart from India, red cabbage can be found throughout Northern Europe, America, and parts of China. 
The potential yield of red cabbage is determined by appropriate husbandry practices and the surrounding environment provided to the crop. Among the husbandry practices, a direct effect can be observed due to an increase or a decrease in plant population because a cabbage plant bears a single head. A very common range in optimum plant population recommendations for cabbage is for stand densities of 20,000 to 70,000 plants per ha (Ghanti et al., 1982; Tenday and Kuzyk, 2001; Kumar and Rawat, 2002). Though many authors have reported some information on the plant density of cabbage, no prominent work has been done on red cabbage. In spite of its greater importance in terms of returns, no systematic research work has been carried out to standardize the suitable agro-techniques for successful cultivation of red cabbage in Andhra Pradesh. Therefore, it is essential to find out the optimum plant densities for yield maximization of red cabbage (Brassica oleracea var. capitata f. rubra) in Andhra Pradesh.

\section{Materials and Methods}

The present investigation was undertaken to study the response of red cabbage (Brassica oleracea L. var. capitata f. rubra) to different levels of plant and row spacing. The experiment was carried out at AICRP on Citrus, Citrus Research Station, Tirupati; Andhra Pradesh during rabi, 2017 under Dr. YSR Horticultural University with the variety Red Jewel.The experiment was laid out in a factorial randomized block design with three replications. The experimental area was divided into plots of $3.5 \mathrm{~m} \times 3.5 \mathrm{~m}$ size with an area of 12.96 sq. m. Irrigation channels of $30 \mathrm{~cm}$ wide were provided for each row of plots. The seedlings were transplanted at a spacing of $45 \times 45 \mathrm{~cm}, 60 \times 45 \mathrm{~cm}$ and $60 \times 60$ $\mathrm{cm}$ in each plot. To raise the crop recommended package of practices were followed. The various parameters were recorded from five randomly selected tagged plants viz., head circumference, volume and compactness, fresh weight, dry matter production, yield per plot and marketable yield. The data was subjected to statistical analysis as per method suggested by Panse and Sukhatme (1967).

\section{Results and Discussion}

\section{Head circumference}

Application of different levels of plating densities showed statistically significant variation for head circumference in red cabbage. Data in table 1 revealed that maximum head circumference $(46.72 \mathrm{~cm})$ was recorded with the lower plant density (60 $\times 60 \mathrm{~cm}$ ) followed by medium plant density $(60 \times 45 \mathrm{~cm})(38.18 \mathrm{~cm})$. However, the minimum head circumference $(35.06 \mathrm{~cm})$ was recorded with higher plant density $(45 \times 45$ $\mathrm{cm})$. The general trend observed was as the plant spacing increased from $45 \times 45 \mathrm{~cm}$ to $60 \times 60 \mathrm{~cm}$, the head circumference was also increased. The lower plant density or wider spacing provides more space where the individual plant enjoyed a maximum suitable environment which resulted for the development of head with maximum circumference. Head circumference decreased as the plant density increased which may be due to competition for light, moisture and nutrients. This can also be attributed to the availability of progressively lower amount of photosynthesis due to the increasing competition among plants for growth factors. Similar result was given by Jett et al., (1995) in broccoli.

\section{Head volume}

It was observed that volume of head differed significantly with planting densities in red cabbage (Table 1). Significantly maximum 
head volume $(1308.70 \mathrm{cc})$ was recorded with $60 \times 60 \mathrm{~cm}$ followed by $60 \times 45 \mathrm{~cm}$ with $1103.49 \mathrm{cc}$ whereas the minimum head volume (976.89 cc) was recorded with $45 \times$ $45 \mathrm{~cm}$. Increased planting densities resulted in reduced head volume in red cabbage. The increase in head volume at wider plant spacing could be probably due to more nutrients, space and moisture availability. This may also be attributed to the low number of plants per unit area, which results in congenial growing conditions such as more space available for growth of roots, shoot and leaves compared to plants in closer spacing. These results are in agreement with Abed et al., (2015) who reported that wider plant spacing $(70 \mathrm{~cm})$ gave the highest values $\left(2974.18 \mathrm{~cm}^{-3}\right)$ of head volume, whereas the closer plant spacing $(50 \mathrm{~cm})$ showed the lowest values $\left(1967.36 \mathrm{~cm}^{-3}\right)$ in cabbage.

\section{Head compactness}

The result of the experiment revealed significant difference among treatments with regard to head compactness (Table 1). It was observed that head compactness differed significantly with planting densities in red cabbage. Significantly maximum head compactness (1.06) was recorded with $45 \times$ $45 \mathrm{~cm}$, followed by $60 \times 45 \mathrm{~cm}(1.12)$ whereas the minimum head compactness (1.16) was recorded with $60 \times 60 \mathrm{~cm}$. Head compactness, which is a primary indicator of horticultural maturity (Radovich et al., 2004), which was positively influenced by increasing plant density.

This can be attributed to the more competition between the plants at higher densities for space and nutrients that led to the formation of highly compact heads. The obtained data was in accordance with results reported by Znidarcic et al., (2007) who indicated that the maximum plant spacing achieved minimum head compactness.

\section{Fresh weight of head}

Plant spacing has significantly influenced average fresh weight of head. Maximum fresh weight of head $(1.15 \mathrm{~kg})$ was obtained with $60 \times 60 \mathrm{~cm}$ followed by $60 \times 45 \mathrm{~cm}(0.97 \mathrm{~kg})$ while, minimum fresh weight was found in 45 $\times 45 \mathrm{~cm}(0.90 \mathrm{~kg})$ (Table 1$)$. It was revealed that with the increase of spacing, fresh weight of plant showed increasing trend. Densely populated plants produced lower fresh weight of head as compared to thinly populated plants. This might be due to the proper utilization of accumulates which were conserved by the plant, under optimally spaced crop. The interplant competition occurred for the available nutrients would have reduced the weights of individual heads in case of high density. These results were well supported by the previous findings of Moniruzzaman (2011) noticed highest head weight $(1090 \mathrm{~g})$ in cabbage at a widest spacing of $60 \times 45 \mathrm{~cm}$ and lowest head weight (1071 g) from the $60 \times 40 \mathrm{~cm}$ spacing. Hossain et al., (2011) recorded maximum head weight $(543.0 \mathrm{~g})$ in $60 \times 60 \mathrm{~cm}$ spacing and minimum head weight $(441.0 \mathrm{~g})$ in $60 \mathrm{x}$ $40 \mathrm{~cm}$ in broccoli. Bhangre et al., (2011) observed maximum (181.54 g) and minimum curd weight/plant (104.14 g) in broccoli at a plant spacing of $60 \times 60 \mathrm{~cm}$ and $45 \times 30 \mathrm{~cm}$, respectively.

\section{Dry matter production}

Red cabbage dry matter production (\%) showed statistically significant variation due to the application of different levels of nitrogen and plant spacings (Table 2). Maximum dry matter production (\%) in red cabbage was recorded $(10.57 \%)$ at lower plant density $(60 \times 60 \mathrm{~cm})$ followed by medium plant density $(60 \times 45 \mathrm{~cm})(10.11$ $\%)$. On the other hand, minimum dry matter production $(9.10 \%)$ was found from $45 \times 45$ $\mathrm{cm}$. 
Table.1 Effect of different plant spacings on yield components of red cabbage

\begin{tabular}{|c|c|c|c|c|}
\hline Treatments & $\begin{array}{c}\text { Head } \\
\text { circumference }\end{array}$ & Head volume & $\begin{array}{c}\text { Head } \\
\text { compactness }\end{array}$ & $\begin{array}{c}\text { Fresh weight } \\
\text { of head }\end{array}$ \\
\hline $45 \times 45 \mathrm{~cm}$ & 35.06 & 976.89 & 1.06 & 0.90 \\
\hline $60 \times 45 \mathrm{~cm}$ & 38.18 & 1103.49 & 1.12 & 0.97 \\
\hline $60 \times 60 \mathrm{~cm}$ & 46.72 & 1308.70 & 1.16 & 1.15 \\
\hline $\mathbf{S . E m} \pm$ & 0.676 & 2.117 & 0.004 & 0.014 \\
\hline $\mathbf{C . D}(\mathbf{P}=\mathbf{0 . 0 5})$ & 2.027 & 6.348 & 0.013 & 0.044 \\
\hline
\end{tabular}

Table.2 Effect of different plant spacings on yield of red cabbage

\begin{tabular}{|c|c|c|c|}
\hline Treatments & Dry matter production & Yield per plot & Marketable yield \\
\hline $45 \times 45 \mathrm{~cm}$ & 9.10 & 23.80 & 183.69 \\
\hline $60 \times 45 \mathrm{~cm}$ & 10.11 & 19.87 & 153.29 \\
\hline $60 \times 60 \mathrm{~cm}$ & 10.57 & 16.23 & 125.21 \\
\hline $\mathbf{S . E m} \pm$ & 0.087 & 0.077 & 0.783 \\
\hline $\mathbf{C . D}(\mathbf{P}=\mathbf{0 . 0 5})$ & 0.261 & 0.232 & 2.350 \\
\hline
\end{tabular}

The fore mentioned results revealed that the wide plant spacing produce heads with larger dimensions and density. The present findings can be attributed to the more competition between the plants at higher densities for space and nutrients that resulted in the negative impact of plant densities on dry matter production. The results are in line with Dragan et al., (2007) in cabbage.

\section{Yield per plot}

Effects of different plant densities on head yield of red cabbage per plot are presented in Table 2. Significantly highest yield per plot $(23.80 \mathrm{~kg} / \mathrm{plot})$ was recorded with the higher plant density $(45 \times 45 \mathrm{~cm})$ which was statistically similar to medium plant density $(60 \times 45 \mathrm{~cm})(19.87 \mathrm{~kg} / \mathrm{plot})$. Lowest yield $(16.23 \mathrm{~kg} / \mathrm{plot})$ was recorded with lower plant density $(60 \times 60 \mathrm{~cm})$. The maximum yield per plot was found superior at higher plant density which was possibly due to more number of plants per unit area; higher ground covers of leaf area resulted in higher light interception and hence, higher assimilate production. Khatun et al., (2011) reported that maximum curd yield/plant (380.88 g) was recorded in broccoli at wider spacing $(60 \times 50$ $\mathrm{cm})$, but yield per plot $(9.64 \mathrm{~kg})$ and per hectare $(16.07 \mathrm{t})$ were found to be higher in closer spacing $(45 \times 45 \mathrm{~cm})$.Similar results have been reported by Sharma and Chaudhary (1996) in cauliflower and Agarwal et al., (2007) in broccoli.

\section{Marketable yield}

Different levels of nitrogen application and spacing significantly influenced marketable yield of red cabbage (Table 2). Highest yield (183.69 q/ha) was recorded with the higher plant density $(45 \times 45 \mathrm{~cm})$ followed by the medium plant density $(60 \times 45 \mathrm{~cm})(153.29$ $\mathrm{q} / \mathrm{ha})$ while, minimum yield (125.21 q/ha) was recorded with lower plant density $(60 \times$ $60 \mathrm{~cm}$ ). The maximum marketable yield was found superior at higher plant density due to more number of plants per unit area; higher ground covers of leaf area resulted in higher assimilates production. The obtained results clearly indicated that although low planting density increased head weight but it failed to compensate the decrease in total yield and the 
highest yield was resulted from the higher planting density. These results match with those obtained by Khatiwada (2000) who mentioned that cabbage head yields were statistically higher $(35 \mathrm{t} / \mathrm{ha})$ at closer plant spacing $(45 \times 20 \mathrm{~cm})$ and Znidarcic et al., (2007) who stated that yield/ha generally increased about $12.5 \%$ as plant spacing increased from 1,08,000 to 1,66,000 plant/ ha. Solunke et al., (2011) noticed that higher curd yield (122.14 q/ha) was recorded in broccoli at a spacing of $60 \times 60 \mathrm{~cm}$ and concluded that yield increment was due to maximum growth parameters like plant height, number of leaves and stem diameter under wider spacing $(60 \mathrm{x}$ $60 \mathrm{~cm}$ ).Similar results have been reported by Agarwal et al., (2007) in broccoli.

From the investigations it can be concluded that among the different plant densities for yield parameters, the yield and yield attributing characters like head circumference $(46.72 \mathrm{~cm})$, head volume $(1308.70 \mathrm{cc})$, fresh weight $(1.15 \mathrm{~kg})$ and dry matter production (10.57\%)showed better expression with lower plant density $(60 \times 60 \mathrm{~cm})$. However, the head yield per plot $(23.80 \mathrm{~kg})$, marketable yield (183.69 q/ha) and compactness (1.06) were found significantly superior with the high density planting $(45 \times 45 \mathrm{~cm})$.

\section{References}

Abed, M.Y, El-Said, E.M. and Shebl, E.F. 2015.Effect of planting date and spacing on yield and quality of Cabbage (Brassica oleracea var. capitata L.).J. Plant Production. 6(12): 2093- 2102.

Agarwal, A, Gupta, S. and Ahmed, Z. 2007. Nitrogen nutrition and plant density influencing marketable head yield of broccoli in cold arid desert of Ladakh. Acta Horticulture. 756: 299 - 307.

Anonymous, 2015-16. National Horticulture Mission, Government of India.

Bhangre, K.K, Sonawane, P.C. and Warade,
S.D. 2011.Effect of different varieties and spacing on growth and yield parameters of broccoli (Brassica oleracea L. var. italica) under Pune conditions. Asian Journal of Horticulture. 6(1): 74-76.

Dragan, Z, Kacjan-Marsic, N, Osvald, J, Pozrl, T and Trdan, S. 2007. Yield and Quality of early cabbage (Brassica oleracea L. var. capitata) in response to within-row plant spacing. Acta Agriculture Slovenica. 89(1): 15-23.

Ghanti, P, Sounda, G, Jana, P.K. and Som, M.G. 1982. Effect of levels of nitrogen, phosphorus and spacing on yield characters of cabbage. Vegetable Science. 9: 1-4.

Hossain, M.F, Ara, N, Uddin, M.R, Dey, S and Islam, M.R. 2011b. Effect of time of sowing and plant spacing on broccoli production. Tropical Agricultural Research and Extension. 14(4): 90-92.

Hossain, M.F, Ara, N, Uddin, M.R, Dey, S and Islam, M.R. 2011b. Effect of time of sowing and plant spacing on broccoli production. Tropical Agricultural Research and Extension. 14(4): 90-92.

Jett, W.L, Ronald, D, Morse and Charles, R.O, Dell. 1995. Plant density effects on single head broccoli production. Horticultural Science. 30(1): 50 - 52.

Khatiwada, P.P. 2000. Plant spacing: A key husbandry practice for rainy season cabbage production. Nepal Agriculture Research Journal. 4: 48-55.

Khatun, K, Saha, S.R and Mostarin, T. 2011. Growth and yield of broccoli as influenced by plant spacing. International Journal of Sustainable Agricultural Technology. 7(12): 7-12.

Mahesh Kumar and Rawat, T.S. 2002. Effect of nitrogen and spacing on the quality and yield of cabbage (Brassica oleracea L. var. capitata). Agric. Sci. Digest. 22 (2): $90-92$.

Moniruzzaman, M. 2011. Effect of plant 
spacings on the performance of hybrid cabbage (Brassica oleracea var. capitata) varieties. Bangladesh J. Agril. Res. 36(3): 495-506.

Panse, M. and Sukhatme, K. 1985.Statistical methods for agriculture workers. Indian Council of Agriculture Research Publications. Pp. 48-67.

Radovich, T.J, Kleinhenz, M.D. and Honeck, N.J. 2004. Important cabbage head traits and their relationship at five points development. Journal of Vegetable Crop production. 10 (2): 19-32.

Sharma, D.K. and Chaudhary, D.R. 1996. Time of sowing and plant density on growth and curd yield in early cauliflower (Brassica oleracea L. var. botrytis) cv. Early Kunwari.Vegetable Science. 23 (2): 141 - 144.

Solunke, B.G, Wagh, A.P, Dod, V.N and
Nagre, P.K. 2011. Effect of dates of planting and spacing on growth and yield of broccoli. The Asian Journal ofHorticulture. 6 (2): 294-296.

Tenday, M. and Kuzyk, K. 2001. Effect of plant density on yielding of cabbage. Vegetable Crops Research Bulletin. 54 (2): 35-39.

Wojciechowska, Rożek, S. and Kołton, A. 2007. The content of some nutrients in red cabbage yield depending on the form of nitrogen fertilizer. Rocz. Akad. Rol. Pozn. Ogrodn. 41: 667-671.

Znidarcic, D, Marsic, N.K, Osvald, J, Pozrl, T. and Trdan, S. 2007. Yield and quality of early cabbage (Brassica oleracea L. var. capitata) in response to within-row plant spacing. Acta Agriculturae Slovenica. 89: 15-23.

\section{How to cite this article:}

Manasa, S., L. Mukunda Lakshmi, Syed Sadarunnisa and Rajasekharam, T. 2017. Response of Red Cabbage (Brassica oleracea L. var. capitata f. rubra) to Different Levels of Plant and Row Spacing. Int.J.Curr.Microbiol.App.Sci. 6(11): 1684-1689. doi: https://doi.org/10.20546/ijcmas.2017.611.202 